\title{
Morocco's agricultural system response to the dual shock of the COVID-19 crisis and drought: learnings and recommendations for the new normal
}

\author{
*Brouziyne, Y. \\ Mohammed VI Polytechnic University (UM6P), International Water Research Institute, Benguerir, 43150, \\ Morocco
}

\author{
Article history: \\ Received: 31 January 2021 \\ Received in revised form: 25 \\ February 2021 \\ Accepted: 2 April 2021 \\ Available Online: 30 June \\ 2021
}

Keywords:

COVID-19,

Agricultural system,

Response to shocks,

New normal,

Morocco

DOI:

https://doi.org/10.26656/fr.2017.5(3).073

\begin{abstract}
As the world looks forward to the new normal after the COVID-19 pandemic, reshaping the agricultural sector and food system is a high priority of most governments. This task is strategic for Morocco due to the vital socioeconomic role of this sector in the kingdom and because of the dual shocks that hit the sector during the 2019/2020 season. This paper aimed to uncover some of the responses of Morocco's agricultural sector to the pandemic and the low rainfall, with a focus on potential opportunities for improvement. Under the increasing recurrence of crises and shocks, systems and organisations are becoming obligated to develop resilience. The Moroccan agricultural system is expected to become more resilient to climate change-induced extremes and the volatility of global food product markets while decreasing its dependence on the international agro-inputs supply chain. Moreover, Morocco's agricultural system should learn to evolve under uncertainty. To succeed in this task, a high level of agility is required across all components of its value chain. Specific leadership and mechanisms should be set up to increase the system's agility in responding to the unpredictable climate and consumer habits; research and development can play an important role in this. Digitalisation can also be a driver of both resilience and agility if adopted across the whole value chain.
\end{abstract}

\section{Introduction}

Over recent months, countries around the world have rushed to contain the spread of the COVID-19 pandemic, which has challenged health systems, political strategies, methods of work, consumption patterns and the prosperity of communities. Resilience, food security, uncertainty, disruption and recovery are among the concepts that have dominated the discourse since the outbreak of the pandemic.

The geopolitical dimension of agriculture has gained tremendous importance in the international agendas of governments and organizations across the world. In addition to classical constraints such as the climate, the global agricultural system faced unprecedented and unpredictable demand for food amid further challenges generated by the pandemic circumstances. In addition to providing food for the population, the agricultural sector is supposed to play an economic role at both the macro and micro levels during and after the health crisis.

As in other economic sectors, the pandemic exacerbated organizational weaknesses and governancerelated imperfections across national food systems. The disruption manifested differently from country to country according to the maturity of the sector, its complexity, its international dependence and its level of resilience to shocks. Shifting toward a more resilient (and more sustainable) food system has been unanimously adopted as a global priority for the post-COVID period.

In Morocco, agriculture is a vital sector with a major socioeconomic role; it has always been considered a key pillar of national development plans. Overall, the COVID-19 disruption to the Moroccan agricultural sector was mitigated by the characteristics of the sector in the kingdom and the government efforts that were qualified as "exemplary" by the FAO's office in Rabat at some stages of the pandemic's spread (FAO, 2020). Nevertheless, multiple opportunities for improvement have become apparent due to pandemic stress and the harsh climate impacts during the growing season.

The main objective of this paper is to highlight the key learnings from the evolution of the Moroccan agricultural system under the double stress of the 2020 health crisis and the dry 2019/2020 season and to contribute to the discussion on the transition of this 
sector in the post-COVID-19 era. After explaining the strategic importance of agriculture for Morocco, we review the response of this sector during a historically challenging year when pandemic impacts joined the effects of a ruthless climate. Considering these elements, an outline of what the new agricultural sector in Morocco should look like in the near future is presented.

\section{A socioeconomically vital sector}

There is a total of 9 million ha of arable land in Morocco, with around $20 \%$ of it irrigated. According to recent official statistics, there are 1.5 million farms, dominated by micro-farms of less than 5ha (up to 70\%). The plant-based production mix is composed of diversified products, but the main crops in terms of dedicated surface area are cereals (5 million ha, mostly rainfed), tree crops such as citrus and olive (1.6 million ha), fodder crops ( 0.4 million ha), Fabaceae ( 0.3 million ha) and vegetables (0.2 million ha) (Ministère d'Agriculture, de Développement Rural et de Pêche Maritime (MADRPM), 2019). In addition to other significant crops in terms of land use, such as sugar beet and oilseed crops, berry crops are gaining importance in many aspects of Moroccan agriculture (around $9000 \mathrm{ha}$ ). The animal husbandry branch in Morocco is also diversified; the national livestock consists of more than 3 million head of cattle, 20 million head of sheep, 5 million head of goats and 170.000 head of camels (MADRPM, 2019). Poultry production is very dynamic in Morocco and recent decades has succeeded in exceeding national demand in terms of meat and eggs.

Agriculture is of major importance in Morocco. From an economic perspective, this sector contributes 11 $-18 \%$ to the national GDP, depending on the climatic conditions during the growing season (Haut Commissariat au Plan (HCP), 2012). Due to its multiple natural assets and state efforts, Morocco is one of the major exporters of fruits and vegetables in the Mediterranean region; the kingdom exports more than 1.3 million tons of fruits and vegetables each year (dominated by tomatoes, citrus, green beans, watermelon and berries), securing around 39 billion MAD of foreign currency funds (MADRPM, 2020a). The social footprint of agriculture in Moroccan society is highly strategic; this sector alone employs more than $40 \%$ of the country's workforce and more than $65 \%$ of the rural population (HCP, 2020; HCP, United Nations, and Bank, 2020). The indirect social impacts of agriculture are tremendous and include maintaining a "social balance" for rural households and contributing to limiting the rural exodus (HCP, 2012).

Since the independence of Morocco in 1956, all governments have made agriculture a driver of national socio-economic development plans through dedicated plans and strategies for the development of this sector. The most recent one, Plan Maroc Vert (2008-2020), succeeded in many aspects of the agricultural value chain. As an example of the positive dynamism of the sector between 2008 and 2018, the annual average growth rate in the production of olives, citrus, red meat, white meat and milk reached $7.4 \%, 6.3 \%, 4.8 \%, 3.8 \%$ and $3.7 \%$ respectively; the annual average growth rate of exports of frozen and fresh fruits, frozen and fresh vegetables, fresh tomatoes and citrus reached13.5\%, $8.5 \%, 5.6 \%$ and $2.5 \%$ respectively (Agrimaroc, 2020).

However, this ambitious plan has not (fully) resolved many of the agricultural sector's weaknesses and vulnerabilities. The very high dependence on climatic conditions and the scarce water resources are major vulnerabilities putting this sector at high risk, especially considering the continuously changing climate in the Mediterranean region. The low integration between the upstream and downstream of the agricultural value chain is another key weakness; a very small ratio of the national production undergoes industrial processing, hence significant added value is missed. Other weaknesses include the very slow digital transition and the unbalanced food trade, as Morocco imports staple food products (e.g., more than 6 million tons of cereals) each year to meet domestic demand (Office National Interprofessionnel des Céréales et Légumineuses, 2020).

\section{The combined crisis}

The first COVID-19 case in Morocco was detected on March $2^{\text {nd }}, 2020$. The Moroccan authorities declared a state of health emergency on March 20th when the country only had a dozen cases. Since then, the pandemic has followed a controlled trend, with an average growth rate of daily infections of around 5.5\% and an average daily fatality rate of $4 \%$ during the containment period. After three months of strict confinement, epidemiological indicators such as the fatality rate decreased and the recovery rate increased, allowing for a gradual easing of the containment by zone from June $10^{\text {th }}, 2020$

2020 was also challenging for the Moroccan agricultural sector from a climatic conditions perspective. With a significant decrease in the cumulative annual rainfall and uneven distribution across the growing period, the 2019/2020 season was not an ideal growing season. Figure 1 shows a comparison between the cumulative monthly rainfall during $2019 / 2020$ and that of a reference growing season calculated over the period 2008 to 2018 in two regions: 

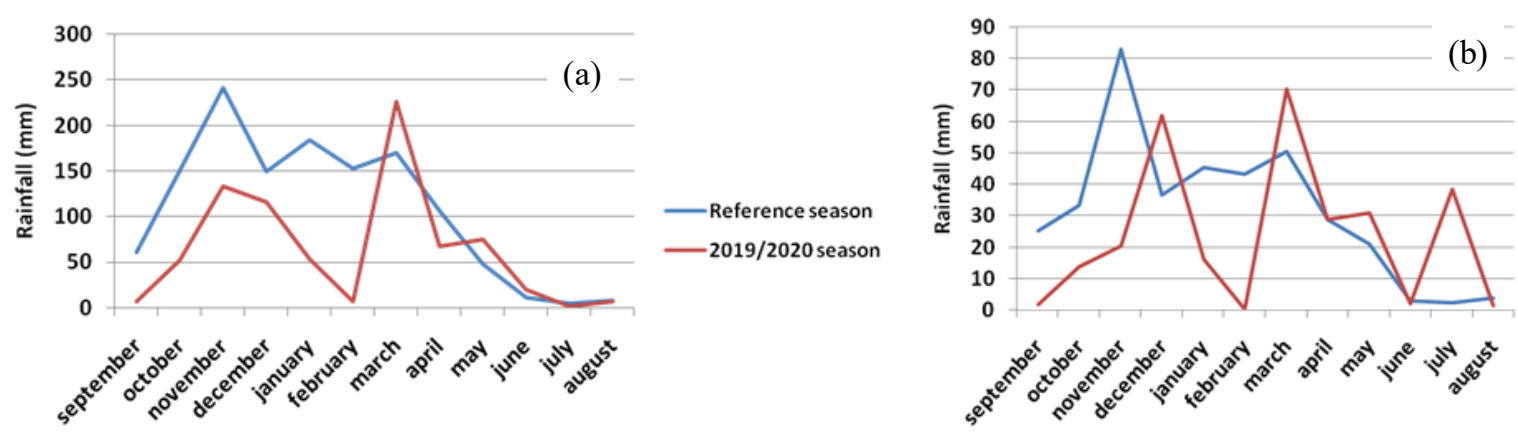

Figure 1. Cumulative monthly rainfall in Sidi Slimane (a) and Benguerir (b).

Source: NASA (2020).

the Sidi Slimane area (north-west of Morocco), considered a favourable area for winter wheat production, where the rainfall deficit was $-40 \%$, and the arid Ben Guerir area (central Morocco), where the deficit was more than $-23 \%$.

The lack of rain was more prominent at the beginning of the growing season (from September to February), corresponding with the most important growth stages of cereals, which was reflected in the national production of cereals this season. 2019/2020's national average yield of cereals was around $6 \mathrm{q} / \mathrm{ha}$ (MADRPM, 2020b), far below the usual $18 \mathrm{q} / \mathrm{ha}$ (MADRPM, 2018). The season's poor rainfall reduced irrigation water availability, affecting the irrigation water supply in the most irrigated parts of the kingdom. Some perimeters saw their supply ceased in the middle of the production period; this was the case for the Chtouka Ait Baha perimeter in the Souss-Massa region, the largest produce exporting area in the country.

\section{Government measures}

Morocco relied on a set of strict measures, extensive financial compensation efforts and a strong sense of solidarity from communities and the private sector to mitigate the effects of the COVID-19 crisis. In addition to restricting mobility and closing borders, schools, and non-essential activities and businesses, the government initiated a series of cross-sector actions to reduce the impact of the restrictions on citizens and businesses.

The government offered businesses possibilities to:

- Postpone or stagger the payment of their contributions to the social security fund;

- Suspend the repayment of the maturities of bank loans and leases without penalties fees;

- Postpone the declaration and payment of tax to the end of June 2020 if the company had a turnover lower than 20 million MAD. Those with a larger turnover and with proved significant disruption of operations could apply for deferred tax payment;
- Benefit from a special emergency line of operating credit for working capital; this measure was dedicated to SMEs.

Regarding individuals, the government put in place an integrated social plan which included:

- The compensation of workers affected by the slowdown or cessation of activity through a monthly lump sum allowance during the pandemic period;

- The speedup of family and insurance allowance procedures;

- The possibility to postpone the repayment of maturities of bank loans.

To cover the emergency socioeconomic measures and support the health sector during the crisis, under royal instruction, a special fund was created. A total of 33.7 billion MAD was collected by the end of July 2020 through contributions from all strata of Moroccan society (the state, the private sector, national NGOs and citizens) (La Vie Eco, 2020).

Specific to agriculture and the food value chain, the government committed to securing a regular supply of food insufficient volumes, either locally produced or imported. To accomplish this goal, the agricultural sector was considered as strategic to pandemic management and benefited from a tailored handling plan in terms of people's mobility and gathering, imports of agro-inputs, and agricultural product imports and exports. Some administrations sped up the digital transition to ease procedures for farmers and agri-exporters and reduce the risks of spreading COVID-19. A primary example is the Easy Food Export solution, powered by FOODEX MOROCCO, a public body in charge of supporting national exports of agri-food products. The Easy Food Export system offers growers and packers the chance to be indexed in the national register of accredited exporters, and to apply for a certificate of product compliance, required for any export operation. Other digital initiatives have emerged, either from public administrations or professional organizations, particularly to promote the e-marketing of local products 
of cooperatives when all domestic markets were shut down.

In addition to this action plan, and to mitigate the impact of the drought, the largest agri-insurance operator in Morocco-the Moroccan Agricultural Insurance Mutual-implemented the compensation plan for insured growers affected by drought two months earlier than in a regular growing season. Moreover, to help livestock breeders struggling with poor grasslands due to the drought, the government subsidised the price of $1 \mathrm{~kg}$ of barley to reduce the cost from $3 \mathrm{MAD}$ to $2 \mathrm{MAD}$.

\section{The agricultural value chain response}

The key forecasts for the Moroccan economy due to the dual shocks are a -5.8 to $-7.2 \%$ economic recession, more than 580.000 jobs lost, a $7.9 \%$ increase in the national budget deficit and an increase in the public treasury debt by $65 \%$ to $76 \%$ of the national GDP (LesEco, 2020). The agricultural sector might have succeeded in securing a steady food supply with no major price changes during the crisis, but it failed to support growth in the national economy during 2020. In its regular quarterly update, the High Commission for Planning (HCP) described recession values starting from $-3.1 \%$ in the 1 st quarter of 2020 to $-7.4 \%$ in the 4 th quarter. In its explanation, the HCP blamed the pandemic -induced disruption to demand, and the poor or unevenly distributed rainfall (HCP et al., 2020).

Even though the Moroccan government gave the national agricultural value chain a special treatment during containment planning, some aspects of the "regular" operations of the sector were affected by the restrictions. At the time of writing this paper, no official quantification of the impacts of the COVID-19 pandemic on agriculture had been performed, but most specialists and stakeholders unanimously agree that the sector has been (directly or indirectly) hit by the double crisis of 2020.

Overall, no major disruption was caused by the restriction of agri-workers' mobility, since this sector was considered "essential" by the authorities. However, the sanitary guidelines led to a reduction in the number of workers who could be transported by vehicle, which increased the cost of workers' transport. The uncertainty caused by the pandemic regarding different aspects of business made attaining agro-input products on credit more complicated since some dealers required cash payment. Generally, a large part of farmers' credit needs in Morocco is supported by agro-input dealers accepting staggered payment for the products.

The unpredictable demand for fruits and vegetables in European markets, especially during the beginning of the coronavirus outbreak, confused the production and the export schedule of the Moroccan growing base. Most of the change involved an increase in volumes, which helped in making this season's exports larger than in the 2018/2019 season. However, the increase in demand from foreign markets during a dry season when irrigation water supply from dams was suspended (especially in the Souss-Massa region) put growers in a very challenging situation as they had to rely solely on very depleted groundwater resources.

Livestock farmers suffered from a series of factors that caused the livestock price to drop significantly during the beginning of the COVID-19 outbreak in Morocco. The main factors were the closing of local markets as part of the containment plan at the 1st stage of the pandemic, the slight drop in demand for red meat and the poor pasture lands due to the lack of rain.

\section{Preliminary learnings and recommendations}

Crises and shocks undoubtedly highlight the strengths and weaknesses of systems; Morocco's agricultural system was put to the test during the 2019/2020 season. No comprehensive assessment has been performed as yet, but preliminary insights into the system's response to shocks are possible. Outlines of the best model to follow under the "new" normal can also be suggested.

Although this paper focuses on the improvement opportunities for the national agricultural value chain in Morocco, it is important to acknowledge the sector's success in fulfilling its food security role during the harsh 2019/2020 season. Market supply of all kinds of food across the kingdom and with normal pricing patterns was exemplary, especially considering that the national food system had to adjust to the disrupted demand pattern during the containment as well as increased demand over Ramadan. This success is attributable to the extensive protection of the government (compared to other economic sectors) and to the different assets of this sector, such as its highly diverse production, and the long technical heritage of its growers and technicians.

\subsection{Resilience}

Almost all specialists expect 2021 to be a year of a shift to the next normal, which will make 2022 very different from 2019. Morocco's agricultural system should acquire a new operating model to cope with any potential crises and unlock its potential under the new global order. Building resilience is key to respond to shocks and crises. Better resilience of the agricultural 
value chain in Morocco could be built by addressing different vulnerabilities such as the local and foreign distribution, marketing systems, the agro-input supply and the inclusivity system. The struggle of livestock farmers during the pandemic in terms of the significant drop in livestock prices should be addressed in the new model from local distribution and marketing perspective. Most of the small-scale farmers in Morocco, including livestock farmers, generally achieve the lowest margin in the whole value chain, since many brokers interfere in domestic agri-product distribution.

In Morocco, most agro-input products are imported; this includes plants and animal health products, vegetable seeds, planting media for soilless farming and many more essential ingredients for agricultural production for the domestic market and export. This high dependence puts Morocco's agricultural system at the mercy of an international supply chain system with low control of its parameters.

The Moroccan agricultural system is run by two types of actors: big farming operations targeting exports and industrial valorization of their production, and smallscale growers performing family farming. Each segment has different roles and expectations. The inclusion of low -income farmers has been a high priority in recent agricultural development plans in Morocco; much has been done but there is still work to do. Agricultural insurance is one of the inclusivity tools that proved to be of high value during the 2019/2020 season and can be used to further increase small-scale farmers' resilience to shocks, especially climatic ones. The resilience of rainfed and irrigated agriculture to climate-induced stresses and water scarcity has always been part of the government's agenda and an ambitious action plan is being executed. The synchronization of its accomplishment with the increasing pressure of the changing climate is one of the criticisms that can be made.

Another aspect of increasing the resilience of exportfocused agriculture in Morocco is the diversification of foreign commercial partners. Morocco's exportation of produce concentrates on Europe and North America. High proportions of some products are shipped to strategic countries such as Spain, France, Germany, Holland, the U.S.A., the U.K. and Russia; these countries account for more than $70 \%$ of Morocco's exportation of produce (UN Comtrade, 2020). In light of this, more efforts are required to split the commercial risk, given that Morocco's growing base can cope with extra demand. Africa and the Gulf region are some of the potential markets.

\subsection{Agility}

Aside from resilience, agility is another concept that emerged during the pandemic in relation to the organizations and societies that excelled. It refers to the ability to respond quickly to change and adapt with as few compromises as possible. In the uncertain time of the pandemic, the agility of governments, organizations, businesses and societies was tested and only the most agile ones succeeded in mitigating the impacts. As an example of the potential room to increase agility in Morocco's export-focused agriculture, it has been proved that there is still much work to be done in terms of strategic and technological intelligence and the monitoring of foreign market dynamics to increase the agility of the grower base during crises. During the 2019/2020 export season, Moroccan growers and exporters heavily relied on their structures to respond to the unpredictable demand patterns during the global health crisis, and the uncertainty regarding the financial capabilities of their foreign partners.

Moroccan organizations involved in the agricultural value chain require agility to respond appropriately to new consumer habits and international supply patterns that are expected to be different in the new normal. The most predicted new trends in consumer habits include increased interest in local products, e-commerce and home-cooking. International trade and the global supply chain will strive to be more cost-effective and governments will aim for self-sufficiency in the essentials of their nations.

Research and development have a significant role to play in exploring the agility horizons of Morocco's agricultural value chain. Sustainable and cost-effective technologies for growing and packing operations, proactive and accurate market monitoring solutions, and reliable and cost-effective supply chain innovations are all required to reshape the Moroccan agricultural system for the post-COVID-19 era.

\subsection{Digitalization}

Digitalization offers much room for improvement in both agility and resilience. Digital agriculture in Morocco is in the nascent stage, but officials have confirmed their willingness to make it an ally of the new Moroccan agricultural system. A few examples of fully operational digital agriculture in Morocco include the setup of the information systems of the ministry of agriculture, e-services offered by some agriculture administrations (e.g., applications for subsidence and compliance certificates, soil fertility maps) and the smart irrigation management implemented by a small group of produce growers. 
This leaves huge room to implement digital solutions across the agricultural value chain to address the aforementioned opportunities for improvement. Ecommerce platforms can help to shorten the distribution loop for small-scale farmers to improve their margins. Eobservatories and simulators of market demand in foreign markets should enable the agility of exportfocused agriculture. Early warnings of drought and other climate change-induced extremes will improve the preparedness of rainfed farmers for these phenomena.

A successful digital transition of the Moroccan agricultural system will have positive impacts on operational excellence, the optimization of efforts and costs and the livelihoods of farmers. Many stakeholders are striving to support this transition and increase its pace; the Mohammed VI Polytechnic University and the OCP Group are among the leading national actors regarding this ambition.

\section{Conclusion}

Morocco's agricultural system is considered as one of the leading ones in the region, allowing the kingdom to export its experience in this sector to other countries within a south-south collaboration framework. This sector contributes to the economic prosperity of the country as far as allowed by the climate and meets most of the national food demand. However, the very harsh 2019/2020 season, marked by the pandemic and drought, highlighted the urgency of speeding up action plans already launched and stressed improvement opportunities across the whole value chain.

This paper identified three aspects to be addressed to reshape the national agricultural system in Morocco: building resilience, acquiring agility and increasing digitalization. Resilience needs to be quickly built (or reinforced) in local and foreign distribution and marketing systems, in the agro-inputs supply chain, in the inclusion of the low-income growing base, and the systems coping with climate change impacts. Agile organizations and leadership are required to respond rapidly and efficiently to volatility during times of crisis and to cope with the expected changes in international trade and consumer behaviour after the pandemic. Research and development can play an important role in expanding the horizons of agility across the whole value chain.

Finally, digitalization has the potential to address both previously mentioned aspects (resilience and agility). The implementation of digitalization in the national agricultural system is still low and there are plenty of opportunities for digitalization along almost the whole agricultural value chain. The good news is that the government is aware of the advantages of technology in agriculture and has made this part of its newly launched Green Generation Plan.

\section{Conflict of interest}

The authors declare no conflict of interest.

\section{References}

Agrimaroc. (2020). Plan Maroc Vert: Les principales réalisations du programme agricole. Actualités Maroc. Retrieved on January 11, 2021 from AGRIMAROC website: https://www.agrimaroc.ma/ plan-maroc-vert-realisations/ [In French].

FAO (Food and Agriculture Organization). (2020). Covid-19: Mesures rapides et ambitieuses prises par le Royaume du Maroc. Retrieved on December 21, 2020 from FAO website: http://www.fao.org/3/ ca9353fr/CA9353FR.pdf [In French].

Haut Commissariat au Plan (HCP). (2012). Agriculture 2030: Quels avenirs pour le Maroc? Retrieved on December 15, 2020 from HCP website: https:// www.hcp.ma/Agriculture-2030-quels-avenirs-pourle-Maroc_a849.html [In French].

Haut Commissariat au Plan (HCP). (2020). Note de conjoncture - Octobre 2020. Retrieved on December 15, 2020 from HCP website: https://www.hcp.ma/ Publication-Note-de-conjoncture-N-37-Octobre2020_a2611.html [In French].

Haut Commissariat au Plan (HCP), United Nations (UN), and World Bank (WB). (2020). Impact social et economique de la crise du COVID-19 au Maroc. Rabat, Morocco: HCP. [In French].

La Vie Eco. (2020). Les grandes mesures pour sauver l'economie. Retrieved on December 9, 2020 from La Vie Eco website: https://www.agriculture.gov.ma/ pages/actualites/une-production-cerealiere-definitive -de-32-millions-de-quintaux-pour-la-campagne-20 [In French].

LesEco. (2020). Récession économique: la Banque centrale persiste et signe. Retrieved on January 9, 2021 from LesEco website: https:// www.agriculture.gov.ma/pages/actualites/uneproduction-cerealiere-definitive-de-32-millions-dequintaux-pour-la-campagne-20 [In French].

Ministère d'Agriculture, de Développement Rural et de Pêche Maritime (MADRPM). (2018). Bilan de la compagne céréalière. Actualités. Retrieved on November 22, 2020 from MADRPM website: http:// www.agriculture.gov.ma/pages/actualites/campagneagricole-2017-2018-les-resultats-definitifs-font-etatdune-recolte-de-103- [In French]. 
Ministère d'Agriculture, de Développement Rural et de Pêche Maritime (MADRPM). (2019). Agriculture en chiffres. Rabat, Morocco: MADRPM. [In French].

Ministère d'Agriculture, de Développement Rural et de Pêche Maritime (MADRPM). (2020a). Bilan positif de la compagne 2019-2020 d'exportation des produits alimentaires agricoles et perspectives prometteuses pour la compagne 202-2021. Rabat, Morocco: MADRPM. [In French].

Ministère d'Agriculture, de Développement Rural et de Pêche Maritime (MADRPM). (2020b). Une production céréalière définitive de 32 millions de quintaux pour la compagne 2019/2020. Actualités. Retrieved on January 12, 2021 from MADRPM website: https://www.agriculture.gov.ma/pages/ actualites/une-production-cerealiere-definitive-de-32 -millions-de-quintaux-pour-la-campagne-20 [In French].

NASA. (2020). The power's project. Retrieved from NASA website: https://power.larc.nasa.gov/

Office National Interprofessionnel des Céréales et Légumineuses (ONICL). (2020). Importations des quatres céréales principales (Juin/Mai). Rabat, Morocco: ONICL. [In French].

UN Comtrade. (2020). UN Comtrade Database: Exports by Country: Morocco. Retrieved on January 16, 2021, from UN Comtrade Analytics website: https:// comtrade.un.org/labs/data-explorer/ 